\section{Mieloma múltiple IgG lambda: derrame pleural mielomatoso, una rara forma de presentación}

\section{Sr. Director:}

El derrame pleural en el mieloma múltiple surge como complicación evolutiva en un $6 \%$ de los pacientes $(3,6,10)$, siendo su etiología variada (Insuficiencia cardiaca por amiloidosis, embolismo pulmonar, insuficiencia renal crónica, infecciosa y neoplásica), sin embargo la afectación mielomatosa pleural con derrame es inusual (7), encontrándose en menos del $0,8 \%$ de casos $(6,9,10)$ siendo en más del $80 \%$ de los casos Mieloma múltiple Ig A $(3,6,10)$ quizás como resultado de su mayor tendencia a invadir estructuras extraóseas.

Describimos el caso de un paciente con múltiple $\operatorname{Ig} \lambda$ que debutó como derrame pleural.

Varón de 55 años de edad con antecedentes de lipomatosis en tórax, hallux valgus en pie izquierdo con dedo en martillo, síndrome dispéptico, intervenido de pólipos laríngeos y actualmente uno en cuerda vocal izquierda en edema de Reincke, hernia discal $\mathrm{L}_{4}-\mathrm{L}_{5}$. Trabajador de caldería en contacto con lana mineral y amianto, ex-fumador desde hace 14 años de 60 cigarros/día y bebedor de 1,1 1/día de vino.

Consultas por un dolor de aparición brusca en base de hemitórax izquierdo, de una semana de evolución, que se irradia hacía escápula izquierda, aumentando en decúbito y mejora en bipedestación, con sensación subjetiva de malestar general, sin tos ni expectoración ni disnea. En la exploración destacaba la existencia de piorrea, faringe eritematosa y seca, con disminución del murmullo vesicular en tercio medio y abolición en el tercio inferior de hemitórax izquierdo, con abolición de las vibraciones vocales en dicha zona; el resto de la exploración física fue normal. La analítica mostraba proteínas totales $=9,08 \mathrm{~g} / \mathrm{dl}$ con el resto de los parámetros dentro de la normalidad, tanto el sistemático como la bioquímica sanguínea y la analítica de orina; VSG $1^{\text {a }}$ hora=10 mm, $\beta 2$-microglobulina=3,2 mg/dl. Hemostasia y ECG sin alteraciones, y en la Rx de tórax y tomografías apareció derrame pleural izquierdo; GSA Fi $\mathrm{O}_{2} 21 \%$ con $\mathrm{Ph}=7,35, \mathrm{pCO}_{2}=43$ $\mathrm{mmHg}$; saturación $\mathrm{O}_{2}=83 \%$; $\mathrm{HCO}_{3}$-mosm/l, y pruebas funcionales respiratorias con resultado de obstrucción ligera.

Mantoux + de $16 \mathrm{~mm}$; microbiología y anatomía patológica del estupo negativos; ecocardiograma con hipertrofia concéntrica ligera y septal moderada, y serología virus hepatitis A, B y C, VIH, CMV, VEB negativa.
El proteinograma detectó la presencia de una banda monoclonal en la región de las gammaglobulinas que correspondió a una Ig G lambda, con Ig M e Ig A disminuidas.

La proteinuria de $24 \mathrm{~h}$, el uroproteinograma y la inmunofijación en orina fueron negativas.

Ante la sospecha de mieloma múltiple se realizó inmunoelectroforesis en suero detectando paraproteína Ig G $\lambda$.

La punción esternal y mielograma mostraron un infiltrado de células plasmáticas del $31 \%$ formado por plasmoblastos, proplasmocitos, y palasmocitos maduros.

La punción pleural y estudio citológico mostró un líquido serohemático, con proteínas $=6,5 \mathrm{~g} / \mathrm{dl}, \mathrm{LDH}=548 \mathrm{U} / \mathrm{l}$, gluco$\mathrm{sa}=110 \mathrm{mg} / \mathrm{dl}$, colesterol=122 mg/dl, ADA=39 (VN<45U/l) $)$, linfocitos $=67 \%$, neutrófilos $=30 \%$, la citología detectó abundantes células plasmáticas atípicas. La serie ósea no identificó lesiones líticas.

Tanto la ecografía abdominal como la gammagrafía con 99 mTc fueron normales, el TAC sólo detectó el derrame pleural, y los marcadores tumorales fueron normales excepto el $\mathrm{Ca}$ $15,3=78,6$ ligeramente aumentado; la RM detectó únicamente hernia discal $\mathrm{L}_{3}-\mathrm{L}_{4}-\mathrm{L}_{5}$.

La exploración ORL fue normal y en una gastroscopia se apreció lesión aguda gástrica antral.

Con los datos obtenidos se hizo el diagnóstico de mieloma múltiple Ig G $\lambda$ estadio II-A, se realizó tratamiento con poliquimioterapia con buena tolerancia, disminuyendo el derrame pleural y la $\beta 2$-microglobulina.

Tratándose el derrame pleural de un exudado descartamos un proceso neoplásico (metastásico, mesotelinoma), infeccioso u otros, con el diagnóstico final de mieloma múltiple y derrame pleural mielomatoso.

Hay pocos casos documentados en el derrame pleural constituye la forma de presentación del mieloma múltiple, siendo inusual la afectación pleural por el propio mieloma. la afectación pleural se puede producir a partir de lesiones esqueléticas o parenquimatosas adyacentes, por infiltración de ganglios linfáticos mediastínicos o por implantación directa en la pleura por vía hematógena, esta última etiología pudo ser la responsable en el paciente referido.

En el periodo que abarca los últimos 10 años 1987-1997, existen 34 casos descritos de derrame pleural mielomatoso, en algunos casos coexistiendo con derrame pericárdico o con ascitis mielomatosa; en 1990 Brabeck y cols. (7) localizó 35 casos previos en la literatura. 
Es más frecuente la localización izquierda $(1,10)$ del derrame pleural mielomatoso, como el paciente referido, aunque no existe explicación fisiopatológica.

Hemos encontrado 8 casos de mieloma múltiple que debutaron clínicamente como derrame pleural mielomatoso, en el periodo recopilado, siendo 3 de ellos Ig G K $(1,8,10), 1$ Ig A K (3), 1 Ig A $\lambda(6), 1 \mathrm{Ig} M \lambda$ (2) y Bence-Jones (4), existiendo sólo uno previamente descrito Ig G $\lambda$ (9) que presentó disnea en vez de dolor torácico, derrame pleural izquierdo, analítica normal excepto el aumento de proteínas con proteinuria de Bence-Jones negativa, con disminución de Ig A e Ig M, serie ósea sin lesiones líticas y VSG aumentada, siendo los dos únicos casos descritos de pacientes que debutan como derrame pleural mielomatoso sin otra manifestación, ya que el los otros casos detectados se asociaban a lesiones osteolóticas u otras manifestaciones acompañantes.

La afectación pleural mielomatosa se ha relacionado con mal $(6,8)$, mala respuesta al tratamiento y supervivencia escasa; normalmente se encuentran en estadio avanzado y tres de ellos el diagnóstico fue realizado en la autopsia.

\section{J. Fernández González, A. C. Matía Cubillo,} R. González Sanz, I. Juárez Redondo, A. Jimeno Carrúez

Servicio de Medicina Interna. Hospital Clínico U niversitario. Valladolid

1. Nieto ML, Soler JJ, Jarque I. Derrame pleural como primera manifestación del mieloma múltiple. Arch Bronconeumol 1997; 70-71.

2. Álvares E, Barroso C, Sotto-Mayor R, de Almeida AB, Freitas e Costa $\mathrm{M}$, Pleural effusion of non neoplastic etiology in a patient with a rare from of myeloma. Acta Med Port 1995; 579-84.

3. Rodríguez JN, Pereira A, Martínez JC, Conde J, Pujol E. Pleural effusion in multipl myeloma. Chest 1994; 105: 622-4.

4. Makino S, Yamahara S, Nagake Y, Kamura J, Bence-Jones. Myeloma with pleural effusion: response to alpha-interferon and combined chemotherapy. Intern Med 1992; 31:617-21.

5. Chen LM, Hwang WS. Myeloma with pleural involvement. Acta Cytol 1991; 35: 372-3.

6. Urritia A, Ribera JM, Rey-Joly C, Foz M. Myelomatous pleural effusion with elevated adenosine desaminase activity. Med Clin (Barc) 1991; 96: 236

7. Brabeck MC, Bubly G, Hunter TJ, Griffith RC. Myelomatous pleural effusion: report of a unusual occurence. Brit Med J 1990; 73: 487-9.

8. Sasser RL, Yam LT, Li CY. Myeloma with involvement of the serous cavities. Cytologic and inmunochemical diagnosis and literature review. Acta Cytol 1990; 34: 479-85.

9. García Pérez AA, Calpe Calpe JL, Carbonell Biot MC, Vilar Zanon A. Myelomatous pleural effusion as the first manifestation of multiple myeloma. Sangre (Barc) 1989; 34: 520-1.

10. Acin P, Woessner S, Sole F, Pedro C. Myelomatous pleural effusion as presentation from of multiple myeloma. Med Clin (Barc) 1996; 106: 799

\section{Osteolisis maxilar, angiomatosis bacilar en infección por VIH}

\section{Sr. Director:}

La angiomatosis bacilar es un proceso proliferativo neovascular de carácter infeccioso con afectación cutánea y/o visceral que afecta con mayor frecuencia a pacientes con infección por el virus de la inmunodeficiencia humana (VIH). Recientemente agrupados dentro del género Bartonella (B.), la B. henselae y B. quintana son los microorganismos involucrados en este tipo de lesión'. Presentamos un caso de angiomatosis bacilar con una inusual forma de presentación, gran lesión fistulizante del maxi- lar superior, como primer síntoma de enfermedad en un paciente infectado por VIH.

Varón de 27 años de edad, consumidor de drogas por vía parenteral. Refiere ulceración bucal tras extracción de $2^{\circ}$ molar superior derecho desde hace tres meses, siendo diagnosticado de infección por VIH y candidiasis oral y tratado con tetraciclinas, penicilina y aztreonam en relación a este proceso, con dudoso seguimiento terapéutico. Ingresa en nuestro Servicio por síndrome febril de 10 días de evolución con astenia, anorexia y tos con escasa expectoración. En la exploración se aprecia elevación térmica $\left(38,5^{\circ} \mathrm{C}\right)$, leucoplasia oral vellosa, candidiasis oral, múltiples adenopatías en cadenas ganglionares accesibles y una gran comunicación fistulizante entre la cavidad oral y nasal a través del paladar óseo, de bordes necróticos. La auscultación cardiopulmonar fue anodina. En abdomen se palpaba hepatomegalia de $6 \mathrm{~cm}$. y esplenomegalia de $4 \mathrm{~cm}$. y en las extremidades se observaron múltiples lesiones cutáneas papulares eritematosas de 0,5 $\mathrm{cm}$ de diámetro. La hematimetría mostró la presencia de desviación izquierda y linfopenia (10\% de cayados, 940 linfocitos $/ \mathrm{mm}^{3}$, linfocitos CD4+26/ $\mathrm{mm}^{3}$ ). En la bioquímica destacaba afectación hepática (GOT 124 U/l, GPT 68 UA, Gamma GT 505 U/l, F. Alcalina 1916 U/l, LDH $660 \mathrm{U} / \mathrm{l}$, hipoalbuminemia $29 \mathrm{gA}$ e hipergammaglobulinemia 4,76 g/l). Los cultivos de sangre, esputo, orina, broncoaspirado, lavado broncoalveolar y heces, así como las serologías frente a hepatitis B y C, toxoplasma, Criptococo, CMV, Leishmania donovani, Brucella, Chlamydia Psiffaci, Coxiella Bumeffi, Legionella, Yersinia y Coccidioides inmitis no aportaron hallazgos relevantes. Se objetivó positividad en las serologías frente a Mycoplasma P neumoniae, Histoplasma capsulatum, VRS, VDRL, TPHA, VIH Ac y VIH Ag. El estudio de LCR fue bioquímicamente normal con serología luética, látex criptocócico y cultivos negativos. La Rx de tórax mostro pequeñas adenopatías hiliares y un patrón intersticial en ambos hemitórax. La Rx de cráneo y ortopantomografia maxilar mostraron una imagen osteolítica en maxilar superior con ocupación del seno maxilar derecho. La ecografía abdominal mostraba únicamente hepatoesplenomegalia. La TAC craneal y el ecocardiograma fueron normales. En la broncoscopia tan sólo se observaron secreciones purulentas. En la punción-aspiración de médula ósea se apreció hipocelularidad sin verse Leishmanias. Se realizó biopsia hepática que mostró una hepatitis granulomatosa con BMR intracelulares, aislándose en su cultivo Mycobacterium Avium-Intracelulare. La biopsia de la lesión oral fue informada como lesión ulcerada con proliferación de vasos, transformación epitelioide de células endoteliales, entremezclados con polinucleares neutrófilos y eosinófilos, siendo similar a la lesión apreciada en la biopsia cutánea que se realizó y ambas sugestivas de Angiomatosis Bacilar. A pesar de ser tratado con trimetroprim sulfometoxazol, eritromicina, ciprofloxacino, rifampicina, isoniacida, pirazinamida, etambutol, cefriaxona y fluconazol el paciente falleció tras 44 días de ingreso, si bien se objetivó desaparición de las lesiones cutáneas y epitelización de su fístula oral (Fig. 1).

La angiomatosis bacilar es un infección bacteriana infrecuente, producida por B. quintana y B. henselae (1), que ocurre comúnmente en situaciones de inmunosupresión, especialmente relacionada con infección por VIH, asociada clínicamente a síntomas y signos constitucionales como malestar general, fiebre, escalofríos, anorexia y pérdida de peso de forma progresiva (2). Las lesiones cutáneas son la forma más frecuente de presentación $(2,3)$, pudiéndose afectar también las mucosas $(2,4,5)$. La afectación visceral con o sin lesiones cutáneas es también frecuente, pudiendo producir lesiones hepáticas o esplénicas (peliosis hepática o esplénica), osteolíticas, linfadenopatías y menos frecuentemente otras localizaciones $(2,3)$. Las lesiones óseas ocurren aproximadamente en el $10 \%$ de los pacientes y pueden aparecer antes de la afectación de otros órganos. Frecuentemente se trata de un foco osteolítico doloroso, mas comúnmente en huesos largos (2), y ocasionalmente localizadas bajo de un 


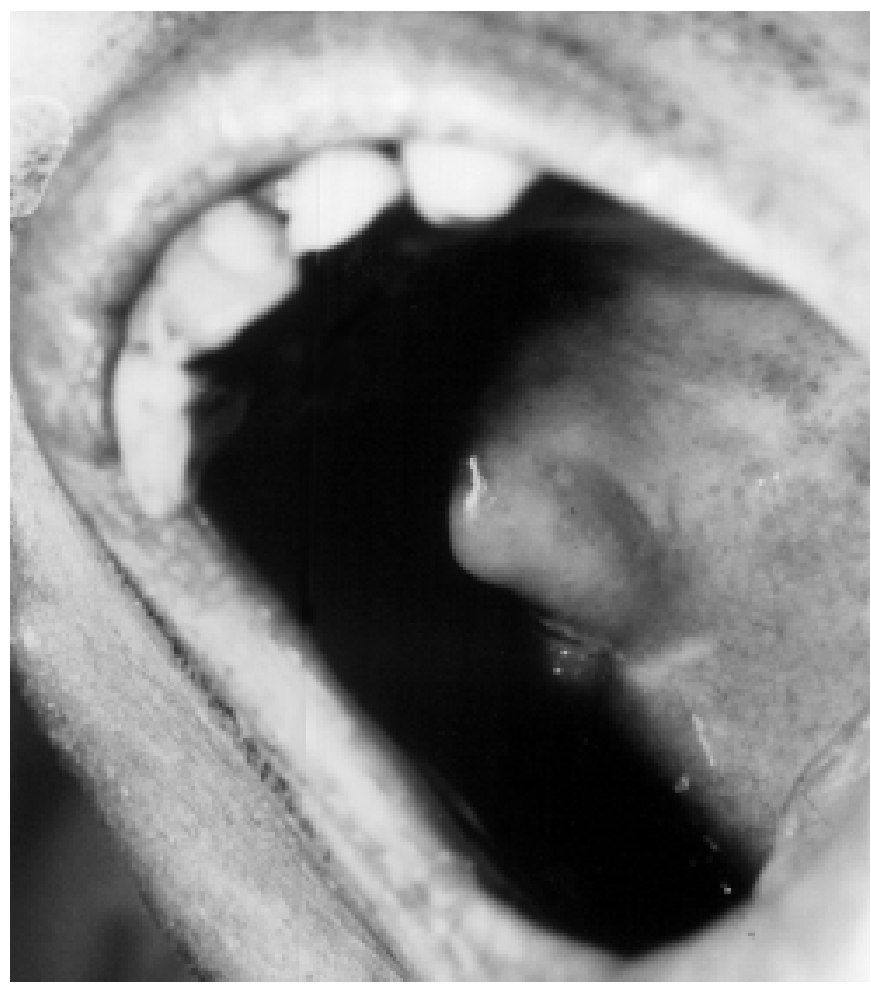

Fig. 1. Cavidad oral. Lesión fistulizante en paladar óseo a nivel del espacio correspondiente al segundo molar superior derecho.

lesión cutánea o mucosa (3). Si bien se han descrito lesiones de la mucosa oral la osteolisis maxilar es infrecuente (4-6). La histopatología de las lesiones es típica, caracterizada por una proliferación vascular lobular con células endoteliales epiteliodes, neutrófilos especialmente alrededor de agregados granulares eosinófilos, los cuales con la tinción de Warthin-Starry muestran numerosos bacilos intra y extracelulares, cuya presencia se puede confirmar con el microscopio electrónico (3). El diagnóstico diferencial debe establecerse con otros procesos con proliferación vascular, especialmente el sarcoma de Kaposi. Las lesiones revierten en tratamiento antibiótico con eritromicina o tetracidinas, no ocurren usualmente recidivas y en la mayoría de los casos no es necesario una terapia crónica (2). Si no se trata adecuadamente la infección puede ser mortal. El interés del caso que presentamos radica en la rareza de su localización y en la intensa destrucción del paladar óseo hasta su fistulización nasal. La evolución desfavorable del paciente se debió a la simultánea asociación con otras infecciones oportunistas y desarrollo de SIDA. Queremos destacar que el diagnóstico de angiomatosis bacilar debe ser considerado en toda persona con infección por VIH con lesiones cutáneo-mucosas de carácter vascular así como en aquellos con cuadros de osteomielitis subaguda.

\section{Metola Sacristán, V. Acha Arrieta, C. Merino Rubio, M. D. García de Lucas, J. M. Casas Fernández de Tejerina}

\section{Servicio de Medicina Interna. Hospital Virgen del Camino.} Pamplona

1. Slater LN, Welch DF. Rochalimaea species (Recently renamed Bartonella). In: Mandell GL, Douglas RB, Bennet JE, eds. Principles and practice of Infectious Diseases. $4^{\mathrm{a}}$ edition. New York: Churchill Livingstone, 1995; 1741-1747.

2. Berger TG. Dermatologic care in the AIDS patient. In: Saunders WB, eds. The medical manegement of AlDS. Filadelfia: Saunders, 1992; 142-175.

3. Adal KA, Cockerell CJ, Petri WA. Cat scratch disease, bacillary angiomatosis, and other infections due to rochalimaea. N Engl J Med 1994; 330: $1509-1515$.

4. Glick M, Cleveland DB. Oral mucosal bacillary epithelioid angiomatosis in a patient with AIDS associated with rapid alveolar bone loss: case report. J Oral Pathol Med 1993; 22: 235-239.

5. Hoffman P, Raspaldo H, Michiels JF, Garnier G, Santini J. Angiomatose bacillaire de la cavité buccab au cours du SIDA. Un diagnostic différentiel du sarcome de Kaposi muqueux. Rev Stomatol Chir Maxillofac 1993; $94: 375-378$.

6. Levell NJ, Bewley AP, Chopra S, Churchill D, French P, Miller R, Gilkes JJH. Bacillary angiomatosis with cutaneous and oral iesions in an HIV-infected patient from the U.K. Br J Dermatol 1995; 132: 113-115.

\section{Metástasis intramedular de un carcinoma no microcítico de pulmón}

\section{Sr. Director:}

Las metástasis intramedulares son raras y generalmente están asociadas a una neoplasia avanzada. En una revisión reciente de la literatura recogen solamente ciento setenta y cuatro casos publicados en el periodo de tiempo entre 1966 y 1994 (1). Frecuentemente las metástasis intramedulares son un hallazgo durante el diagnóstico diferencial de una compresión medular en un paciente con cáncer y en raras ocasiones son la forma de presentación de una neoplasia. Su diagnóstico se ha facilitado en los últimos años con el desarrollo de las técnicas de imagen. Dada su rareza creemos de inter comunicar un nuevo caso en un paciente con cáncer no microcítico de pulmón y comentar algunos aspectos diagnósticos de este problema.

Se trata de un varón de 61 años diagnosticado previamente de una metástasis parieto-occipital izquierda que fue resecada. La anatomía patológica mostró un carcinoma de células grandes. Posteriormente recibió radioterapia holocraneal. En el estudio de extensión inicial se observó una tumoración de $\mathrm{cm}$ en el lóbulo superior izquierdo sin adenopatías mediastínicas en la TAC. La fibrobroncoscopia fue normal.Mientras estaba pendiente de cirugía torácica el paciente ingresó por dorsalgia con paraparesia de miembros inferiores de rápida evolución estreñimiento y retención urinaria. Se realizó una resonancia nuclear magnética de columna que sólo mostró una imagen intramedular hipercaptante con gadolíneo a nivel de D7-D8 (Fig. 1) sugestiva de metástasis. Fue tratado con dexametasona a dosis altas y recibió radioterapia sin mejoría sintomática. Durante el ingreso se demostró también una progresión locorregional del tumor primario.

Las metástasis intramedulares representan el 0,85 a 3,9. de las metástasis espinales sintomáticas (1). La causa más frecuente de metástasis intramedulares es el cáncer de pulmón $(1,2)$ y en esta localización la histología más frecuente es el carcinoma microcítico (2). En segundo lugar pero mucho menos frecuentes están el melanoma y el cáncer de mama. La clínica de las metástasis intramedulares se caracteriza por una mielopatía de rápida evolución lo que las diferencia de los tumores primarios medulares que tienen una evolución más lenta. La resonancia nuclear magnética es la prueba diagnóstica clave en aquellos pacientes en los que se sospeche la presencia de metástasis intramedulares $(1,3)$. El uso de contrastes paramagnéticos es muy útil para el diagnóstico $(4,5)$ como también demostró nuestro caso. Por último la utilización de la tomografía por emisión de positrones en los estudios de extensión de ciertos tumores como el cáncer de pulmón podría permitir el diagnóstico precoz de metástasis inesperadas a nivel intramedular (6) que se confirmarían posteriormente con una resonancia nuclear magnética. 


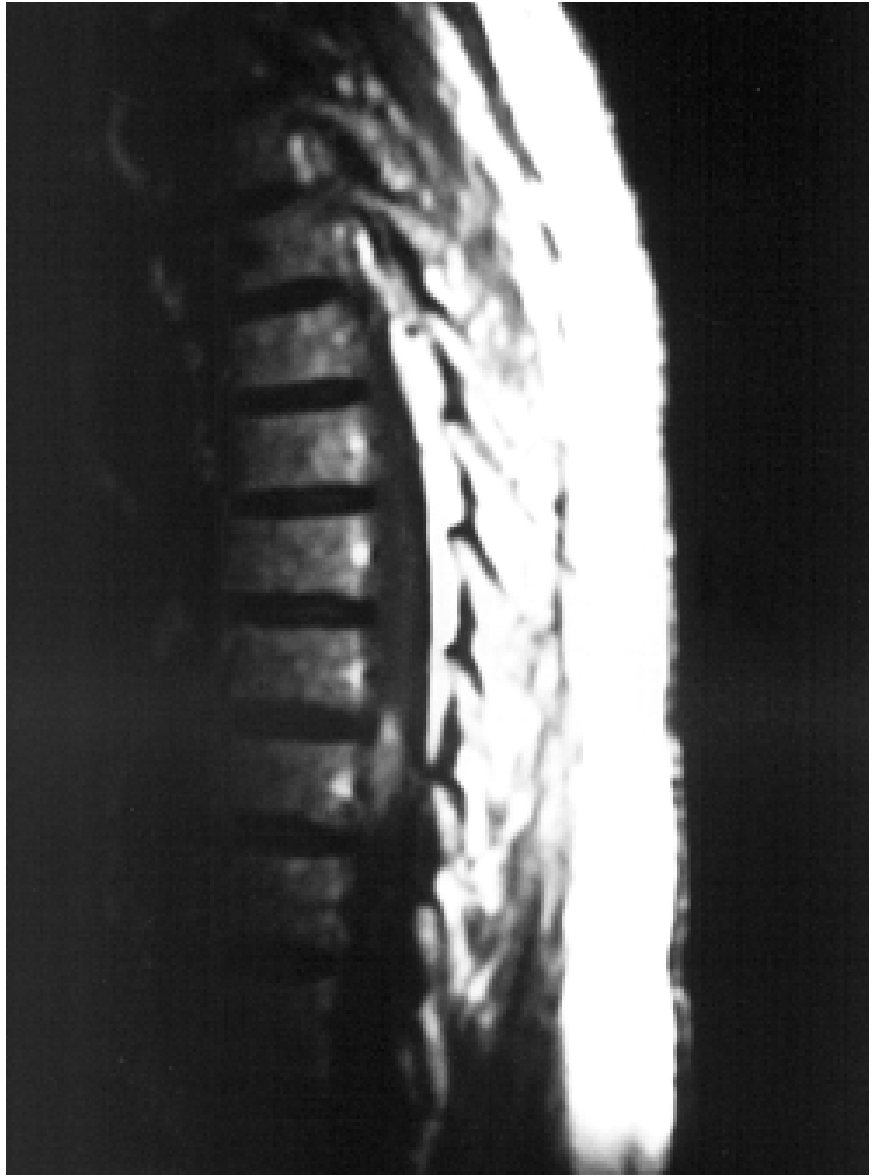

Fig. 1. Resonancia en tiempo T1 con gadolinio, corte sagital.

\section{J. M. Barón Saura*, R. Yagüe Águeda**, S. Hernández***}

*Unidad de Oncología Médica. **Unidad de Medicina Interna. ***Servicio de Radiología. Clínica Moncloa. ASISA. Madrid

1. Connolly ES Jr, Winfree CJ, McCormick PC, Cruz M, Stein BM. Intramedullary spinal cord metastasis: report of three cases and review of the literature. Surg Neurol 1996; 46: 329-337.

2. Costigan DA, Winkelman M . Intramedullary spinal cord metastasis. A clinicopatholgical study of 13 cases. J Neurosurg 1985; 62: 227-233.

3. Li MH, Holtas S. MR imaging of spinal intramedullary tumors. Acta Radiol 1991; 32: 505-513.

4. Stimac GK, Porter BC, Olson DO, Gerlach R, Genton M. GadoliniumDTPA-enhanced MR imaging of spinal neoplasms: Preliminary investigation and comparison with unenhanced spin-Echo and STIR sequences. AJR 1988; 151: 1185-1192

5. Lauvin R, Cornu P, Philippon J, Gautier JC, Jacquillat C, Khayat D Doyon D. Isolated cervical intramedullary metastasis from breast cáncer. Value of magnetic resonance imaging. Rev Neurol Paris 1988; 144: 40-42.

6. Jayasundera MV, Thompson JF, Fulham J. Intramedullary spinal cord metastasis from carcinoma of the lung: Detection by positron emission tomography. Eur J Cancer 1997; 508-509.

\section{Coma secundario por intoxicación por atropina como intento autolítico}

Sr. Director:

El coma es uno de los cuadros sindrómicos que podemos ver en un Servicio de Urgencias y que puede plantear dificultades diagnósticas importantes. Tras la evaluación inicial junto con las exploraciones complementarias (analítica en sangre, en líquido cefalorraquídeo y mediante técnicas de imagen) podemos llegar al diagnóstico etiológico en un número importante de casos (1) . A veces a pesar de estos datos, se concluye con la posibilidad de coma de origen tóxico. Si los familiares aportan información de los posibles tóxicos consumidos o hay algún dato típico en la exploración o en los complementarios, el tóxico puede sospecharse e iniciarse un tratamiento contra éste (2). Cuando no se dan estas circunstancias, el descubrimiento del tóxico ingerido es una labor detectivesca.

Presentamos a continuación el caso de un enfermo que fue traído al hospital con un cuadro de coma junto con datos de bloqueo colinérgico debido a un intento de suicidio mediante la ingestión oral de un colirio de atropina.

Varón de 22 años que es traído al hospital por su familia por encontrarlo en su habitación con intensa agitación psicomotriz seguido de disminución progresiva del nivel de conciencia. No referían que hubiera presentado fiebre, cefalea, traumatismo craneal ni otra sintomatología los días previos. No referían antecedentes personales de interés y no tomaba ninguna medicación habitual. Era enfermero de profesión y su padre regentaba una farmacia.

En la exploración física se encontraba con una temperatura de $37,8^{\circ} \mathrm{C}$, una frecuencia cardiaca de $100 \mathrm{Ipm}$ y una TA normal. La piel estaba seca y no presentaba señales de venopunción. El resto de la exploración somática fue normal. En la exploración neurológica se encontraba en coma, sin apertura palpebral ni respuesta verbal ante ningún tipo de estímulo. Las pupilas eran midriáticas y arreactivas. Presentaba postura de descerebración bilateral ante estímulos dolorosos con reflejo cutáneo plantar extensor bilateral. Los reflejos corneales y oculocefálicos estaban intactos y no había movimientos desconjugados oculares.

El hemograma, bioquímica básica, el CT y RMN cerebral, y la punción lumbar fueron normales. Se obtuvo muestra para tóxicos y se inició tratamiento empírico con oxigenoterapia, glucosa, vitamina B1 y flumazenil sin objetivarse respuesta positiva. El paciente ingresó en UCI con el diagnóstico de coma de probable origen tóxico. A las 48 horas comenzó a recuperar de forma progresiva el nivel de conciencia quedando en su situación previa unas 10 horas después sin focalidad neurológica alguna. Interrogado el enfermo confesó haber ingerido 2 frascos de colirio de atropina (sulfato de atropina al 1\%) con fines autolíticos.

Discusión: en el enfermo que se presenta en coma de origen tóxico es fundamental el realizar una exploración física con detalle que puede darnos una idea del grupo farmacológico implicado: anticolinérgicos, colinérgicos o simpaticomiméticos (2).

En nuestro caso presentaba un coma con datos de bloqueo colinérgico: midriasis, piel seca, taquicardia, etc. Los grupos farmacológicos que con mayor frecuencia producen este tipo de toxicidad son los antidepresivos tricíclicos, los antihistamínicos, los antisicóticos y los antiparkinsonianos $(2,3)$.

En ocasiones se describen casos clínicos esporádicos de síndromes anticolinérgicos como consecuencia del consumo de alcaloides de la belladona como es la atropina. Los casos descritos de intoxicación por atropina han sido habitualmente accidentales como varios casos asociados a la toma de té en hojas (4-6), al utilizar colirios de anticolinérgicos (7) o al utilizarla vía i.v. en adictos (8).

Este es el primer caso descrito de intoxicación por atropina (mediante la ingestión oral de colirio) con fines suicidas. El tipo de profesión del paciente (diplomado de enfermería) junto con la de su padre (regentaba una farmacia) hizo posible este intento de suicidio tan excepcional. Ante intoxicaciones en individuos que dispongan de acceso a muchos fármacos, el diagnóstico de sospecha del fármaco implicado puede ser muy difícil. 


\section{J. Pardo Moreno, M. Castro del Río, C. Martín Estefanía, E. Pintor Holguín*}

Servicios de Neurología y *Medicina Interna III. Hospital Uni versitario San Carlos. Madrid

1. Samuels MA. The evaluation of comatose patients. Hosp Pract 1993; 28: $165-82$.

2. Liang HK. Clinical evaluation of the poisoned patient and toxic syndromes. Clin Chem 1996; 42: 1350-55.

3. Dorado S, Martín J, Sabugal G, Caballero PJ. Epidemiología de la intoxicación aguda: estudio de 613 casos en la comunidad de Madrid en 1994. Rev Clin Esp 1996; 196: 150-6.

4. Hsu CK, Leo P, Shastry D, Meggs W, Weisman R, Hoffman RS. Anticholinergic poisoning associated with herbal tea. Arch Intern Med 1995; 155: 2245-8.

5. From the Centers for Disease Control and Prevention. Anticholinergic poisoning associated with herbal tea. New York city, 1994. JAMA 1995; 15: 1166-7

6. Anticholinergic poisoning associated with herbal tea. New York city, 1994. MMWR 1995; 44: 193-5.

7. Nadal J, De la Fuente V, Abadías M, Torrent J, Jane F. Toxic coma induced by anticholinergic eye drops. Br Med J 1987; 295: 1352.

8. Rodríguez A. Coma febril con polinucleosis por intoxicación por atropina. An Med Interna (Madrid) 1992; 9: 414.

\section{Broncoespasmo en relación con heroína inhalada}

\section{Sr Director:}

La asociación entre el consumo de heroína por vía inhalatoria calentada sobre papel de aluminio y cuadros clínicos superponibles al asma bronquial han sido sugeridos en trabajos previos $(1,2)$. El episodio asmático puede ser severo, requiriendo ventilación mecánica e incluso provocar la muerte (3). Dado que el consumo de heroína inhalada es una variante de drogadición relativamente extendida en los últimos años, creemos oportuno comunicar estos tres casos, para enfatizar su papel etiológico en crisis de asma agudo.

Varones de edad joven, fumadores de tabaco habitual e inhaladores de heroína desde hace 1,5 años, no adictos por vía endovenosa. No antecedentes de exposición laboral a ningún alérgeno conocido. No historia de atopía familiar o personal. Ingresan por un cuadro aislado de disnea sibilante progresiva de diferente tiempo de evolución, compatible con cuadro clínico de broncoespasmo, sin claro factor desencadenante infeccioso o alérgico. En la tabla I se exponen sus características clínicas, físicas, y los diferentes estudios complementarios. Tratados con oxigenoterapia, salbutamol nebulizado y corticoterapia sistémica experimentaron una rápida mejoría clínica y absoluta normalización de los gases arteriales y del pico flujo espiratorio máximo. La espirometría basal, prueba broncodilatadora y pruebas cutáneas en periodo estable fueron normales.

La incidencia de crisis asmáticas por el uso de inhalación de heroína en pacientes sin antecedentes de asma se desconoce pues hay observaciones muy aisladas (4). Esta morbilidad se incrementa en la población con antecedentes de atopía. A excepción del papel que pueda desempeñar el tabaco, el hábito tóxico es el único aparente factor capaz de desencadenar broncoespasmo en estos casos. La asociación temporal es evidente, aunque el intervalo de tiempo de aparición del cuadro clínico tras iniciar la inhalación de heroína es variable. El mecanismo patogénico no está claro (5), pero probablemente sea multifac-
TABLA I

CARACTERÍSTICAS CLÍNICAS, FÍSICAS Y PRUEBAS COM PLEM ENTARIAS DE LOS TRES CASOS REVISADOS

\begin{tabular}{|c|c|c|c|}
\hline Casos & 1 & 2 & 3 \\
\hline Edad (años) & 27 & 36 & 39 \\
\hline $\begin{array}{l}\text { Tiempo evolución } \\
\text { de la disnea }\end{array}$ & $\begin{array}{l}6 \\
\text { (meses) }\end{array}$ & $\begin{array}{l}1 \\
\text { (meses) }\end{array}$ & $\begin{array}{l}4 \\
\text { (días) }\end{array}$ \\
\hline Temperatura $\left({ }^{\circ} \mathrm{C}\right)$ & $<37^{\circ}$ & $37,3^{\circ}$ & $<37^{\circ}$ \\
\hline $\mathrm{TA}(\mathrm{mmHG})$ & $120 / 80$ & $150 / 100$ & $110 / 70$ \\
\hline FC/FR (por minuto) & $80 / 24$ & $80 / 20$ & $120 / 20$ \\
\hline$A P$ & sibilancias & roncus & sibilancias \\
\hline Eosinófilos $\left(10^{3} \times \mu l\right)$ & 1.343 & 150 & 233 \\
\hline $\lg E$ UI/M L & $<100$ & $<100$ & $<100$ \\
\hline Rx tórax & normal & normal & normal \\
\hline $\begin{array}{l}\mathrm{pH} / \mathrm{pCO}_{2} / \mathrm{pO}_{2} \\
(\mathrm{mmHg})\end{array}$ & $7,38 / 43 / 53$ & $7,50 / 32 / 52$ & $7.39 / 47 / 54$ \\
\hline PEF inicial (I/min) & 170 & 180 & 145 \\
\hline Serología VIH & negativa & negativa & negativa \\
\hline
\end{tabular}

TA: tensión arterial. FC: frecuencia cardiaca. FR: frecuencia respiratoria. AP: auscultación pulmonar. PEF: pico máximo.

torial: opiáceos que favorecen la liberación de histamina, depresión del sistema respiratorio central, sustancias que adulteran la heroína y/o los vapores de aluminio que se desprenden al recalentarla y provocarían hiperreactividad bronquial. Estudios realizados en personas expuestas laboralmente a los vapores de aluminio han demostrado clínica de asma bronquial (6). Se requerirían test diagnósticos específicos con preparados de aluminio y heroína, aislados, para dilucidar cúal de los diferentes elementos son los responsables del cuadro clínico. La respuesta clínica al tratamiento convencional ha sido muy favorable.

Ante el uso extendido de este tipo de drogadición y por su gravedad potencial debe ser reconocido precozmente por sus implicaciones pronósticas, e incluirlo como una causa más en la amplia lista de asma agudo.

\section{Izquierdo Patrón, J. Martínez-Moratalla, G. González Valladeres}

Sección de Neumología. Hospital General de Albacete. Albacete

1. Iglesias A, Gómez J, El-Khatib I, Fernández F. Crisis asmática por heró́na inhalada. Rev Clin Esp 1994; 194 (9): 731-732.

2. Otero Candelera R, Sánchez Gil R, Capote Gil F, Pereira Vega A, Hernández Utrera F, Castillo Gómez J. Obstrucción e hiperreactividad bronquial en relación con la inhalación de heroína y vapores de aluminio. Estudio de 20 casos. Arch Bronconeumol 1993; 29 (6):281-285.

3. Hughes S, Calverley PMA. Heroin inhalation and asthma. BMJ 1988; 297: 1511-1512.

4. Oliver RM. Bronchospasm and heroin inhalation. Lancet 1986; 1: 915.

5. Santos-Sastre S, Capote-Gil F, González-Castro A. Airway obstruction and heroin inhalation. Lancet 1986; 2: 1158.

6. Abramson MJ, Wlodarczyk JH, Saunders NA, Hekley M. Does aluminium smelling cause lung disease?. Am Rev Respir Dis 1989; 139: 1042 1057 


\section{La Unidad de Corta Estancia Médica (UCEM) de A Coruña: cumplimos cinco años}

\section{Sr. Director:}

Barbado y cols. (1) publicaron en su Revista la experiencia de la Unidad de Corta Estancia dependiente de Medicina Interna del Hospital Clínico Universitario de Valladolid. En primer lugar queremos felicitarles, no sólo por el artículo publicado sino por el trabajo diario que refleja dicho estudio. Como médicos que trabajamos en la UCEM de A Coruña sabemos que los resultados por ellos obtenidos no serían posibles sin entrega y entusiasmo en el trabajo de todos los días.

En 1997 publicamos en su Revista el análisis de nuestro primer año de experiencia (2). En Abril de 1999 cumplimos los cinco años desde que se inauguró nuestra Unidad, y en septiembre de este mismo año presentamos el resumen de nuestra actividad en estos años en el VII Congreso de la Sociedad Madrid-Castilla La Mancha que se celebró en Toledo (3). Continuamos trabajando en la Unidad 4, adjuntos de Medicina Interna dirigidos por el Jefe del Departamento en una planta de hospitalización con capacidad para 41 pacientes y con una consulta diaria. Los datos más relevantes de la actividad los recogemos en la tabla I.

Los resultados del funcionamiento de nuestra UCEM en el primer año son bastante superponibles a los descritos por Barbado y cols. Creemos que la diferencia en el número de pacientes atendidos refleja la distinta disponibilidad de camas y de médicos trabajando en las dos UCEM. La edad de los pacientes es similar, y también coincide el franco predominio de varones. Pensamos que existe una relación inversa entre pacientes trasladados y estancia hospitalaria. Barbado y cols. tienen una estancia más corta que la nuestra (2,37 vs $3,22 \%)$, y en cambio el porcentaje de traslados es discretamente mayor $(37,6$ vs $32,1 \%)$ (1).

A lo largo de los años la UCEM de A Coruña ha mejorado su rentabilidad aumentando significativamente el número de pacientes ingresados en ella de 1.814 en el 94 a 3.206 cinco años después. Por los datos que tenemos hasta el momento, el año 1999 presentará resultados casi idénticos a los de 1998, por lo que parece estabilizarse la cifra de ingresos en torno a los 3.200 pacientes al año, manteniendo una estancia media que globalmente ha sido de 3.45 días.

En estos 5 años no ha cambiado el paciente tipo manteniéndose la misma edad, sexo y diagnósticos más frecuentes, que fueron: insuficiencia cardíaca $(12,3 \%)$, EPOC $(8,9 \%)$, angor inestable $(7,8 \%)$, dolor torácico inespecífico $(6,9 \%)$, arritmia cardiaca $(4,6 \%)$ y ACVA $(3,2 \%)$. El estudio de Barbado y cols. presenta los diagnósticos agrupados por aparatos o sistemas (1), pero probablemente sean muy superponibles a los nuestros, salvo, quizás, por un número más bajo de enfermos con problemas cardíacos en Valladolid.

Queremos destacar que en estos 5 años en A Coruña han disminuido los traslados a Unidades convencionales del 32,1 al
$15,5 \%$ de 1998, sin que aumentase de forma llamativa la estancia. Estamos absolutamente convencidos que la existencia de una Consulta Externa ágil y sin demoras, apoyando a la planta de hospitalización, es una de las piezas fundamentales para conseguir este objetivo. Como se refleja en la Tabla I el número de pacientes que revisamos ambulatoriamente aumentó de forma exponencial a lo largo de estos años y hemos aprendido a mejorar la labor desempeñada en dicha Consulta.

Estamos de acuerdo con Barbado y cols. (1) que, en ocasiones, los servicios hospitalarios funcionan con estructuras y conceptos no modificados a lo largo de muchos años. La Medicina Interna entendida como especialidad exclusivamente intrahospitalaria, sin relación con la actividad ambulatoria y la Atención Primaria, es probablemente una visión cicatera de la especialidad, y una merma en la calidad de la atención ambulatoria que pueden recibir los pacientes, al privárseles de médicos específicamente entrenados para valorar con visión globalizadora sus problemas de salud. Tenemos el pleno convencimiento de que las Unidades de Corta Estancia Médicas pueden contribuir a un cambio en el modelo de hospital hacia el que caminamos, en el que eficiencia, estancia adecuada, etc. serán puntos de referencia del quehacer diario. Estas Unidades tienen más razón de ser en hospitales de gran complejidad organizativa, como los de Tercer Nivel en los que con mucha frecuencia se vive la "esquizofrénica situación" de poder trasplantarle a un paciente varios órganos a la vez, y encontrarse el hospital bloqueado por sobresaturación de pacientes con patología muy prevalente ("poco trasplantable", si nos permiten utilizar un tono humorístico), que "alguien" debe gestionar con la mayor eficiencia posible. Para nosotros, "alguien" igual a "médicos internistas".

\section{F. de la Iglesia Martínez, V. Ramos Polledo, C. Pellicer Váz- quez, R. Nicolás Miguel, F. Diz-Lois Martínez}

Unidad de Corta Estancia Médica (UCEM). Complexo Hospita lario Juan Canalejo. A Coruña

1. Barbado Ajo MJ, Jimeno Carruez A, Ostolaza Vázquez JM, Molinero de Dios J. Unidad de corta estancia dependiente de Medicina Interna. An Med Interna (Madrid) 1999; 16: 504-510.

2. De la Iglesia Martínez F, Pellicer Vázquez C, Ramos Polledo V, Castro Romero B, Rodríguez Sotillo A, Diz-Lois Martínez F. La unidad de corta estancia médica (UCEM) de la Coruña: nuestra experiencia. An Med Interna (Madrid) 1997; 14: 125-127.

3. De la Iglesia Martínez F, Lorenzo López JA, Ramos Polledo V, Pellicer Vázquez C, Nicolás Miguel R, Diz-Lois Martínez F. Cinco años de corta estancia en A Coruña. Abstract de presentación oral del VII Congreso de la Sociedad Madrid Castilla-La Mancha de Medina Interna, Toledo. An Med Interna (Madrid) (N. ${ }^{\circ}$ ext.) Septiembre 1999; 20-21.

TABLA I

ACTIVIDAD DE LA UNIDAD DE CORTA ESTANCIA M ÉDICA DE A CORUÑA, 1994-1998

\begin{tabular}{llllll}
\hline & 1994 & 1995 & 1996 & 1997 & 1998 \\
\hline $\mathrm{N}^{\circ}$ de ingresos (pacientes) & 1.814 & 1.983 & 2.414 & 3.053 & 3.206 \\
Estancia media (días) & 3,22 & 3,51 & 3,62 & 3,25 & 3,63 \\
Consultas Externas (n. ${ }^{\circ}$ pac.) & 216 & 682 & 1.611 & 1.959 & 2.981 \\
Pacientes trasladados (\%) & 32,1 & 24,7 & 23,2 & 19,2 & 15,5 \\
Edad media (años) & 64,71 & 64,75 & 64,85 & 65,01 & 64,89 \\
Varón/M ujer (\%) & $57,8 / 42,1$ & $59,5 / 40,4$ & $58,6 / 41,5$ & $59,2 / 40,7$ & $59,3 / 40,6$ \\
\hline
\end{tabular}




\section{A propósito de una consulta especializada de hipertensión arterial}

\section{Sr Director:}

He leído con mucho interés la revisión, publicada en su Revista, que realizan Valero Capilla y Masana Marín (1) sobre las características de una consulta de hipertensión arterial a nivel hospitalario. Me llama la atención una serie de cuestiones que no quedan claras o son sorprendentes en su estudio.

Es llamativo que siendo una consulta de nivel hospitalario de la asistencia sanitaria, y por lo tanto lugar de referencia del Área Sanitaria, la cantidad de pacientes remitidos desde Atención Primaria, sea muy escasa. También sería conveniente conocer desde qué tipo de consultas del Hospital eran enviados los pacientes y sí en el mismo hospital existen otras consultas, monográficas o no, llevadas por otras especialidades que pudieran introducir cierto sesgo en el tipo de pacientes atendidos, lo que daría lugar a unas frecuencias de patologías concomitantes, en cierta medida, distorsionadas.

Que el número de pacientes, ya tratado farmacológicamente cuando se incorporan a la consulta, sea tan elevado, puede distorsionar el estudio inicial ya que es lógico pensar que los pacientes estarían en parte controlados o con cierto grado de protección, gracias a los fármacos que tomaban.

Es realmente sorprendente el gran número de urografías intravenosas y angiografías aorto-renales que se hacen, lo que quizás hace pensar que los estudios están muy orientados a patologías renales, por lo que tal vez la patología renal, como causa de hipertensión secundaria, esté sobredimensionada. Por otra parte, el número de exploraciones ecocardiográficas es escaso pensando en que, por la procedencia de los enfermos, muchos tendrán patologías cardiacas ya desarrolladas, como lo demuestra el número de complicaciones cardiovasculares graves que presentan los pacientes y de los factores de riesgo asociados, aunque como indican dichas complicaciones, en su mayor parte ya las habían presentado. No se comenta sí a los pacientes se les realizó monitorización de la presión arterial ambulatoria, estudio tan necesario para valorar tanto si el control de la tensión arterial es verdadero durante las 24 horas, o sí los pacientes presentan el fenómeno de "hipertensión de bata blanca", tan frecuente en consultas hospitalarias.

Se comenta que el número de pacientes que alcanzaron un nivel óptimo de control tensión es del $31 \%$, pero dado que más de la mitad, 342 en total, si sumamos los que pasaron a control ambulatorio y los sujetos que no se presentaron a sucesivas revisiones, de los pacientes incluidos en el estudio, no se podrá saber cuál es el número real de controlados ya que, como es sabido, a lo largo del tiempo los pacientes que, en un principio están bien controlados, pueden dejar estarlo por infinidad de situaciones, como es el abandono de tratamiento parcial o total, las complicaciones médicas que se van inexorablemente presentando, etc.

Otro punto al que no se refieren, es la incidencia de complicaciones cardiovasculares y fallecimientos que ocurren durante el periodo analizado. Es lógico pensar que durante el seguimiento de los pacientes, incluso en los que la tensión arterial está óptimamente controlada, algunos habrán tenido eventos clínicos que precisarían ingreso en su hospital, así como su inevitable fallecimiento, y dado que un gran número de pacientes actualmente mueren en el hospital, se podría haber hecho un análisis de los patologías y causas de fallecimiento durante el periodo analizado, lo que nos podría corroborar, una vez más, la gran necesidad de un mejor control de la hipertensión arterial.

\section{M. Cuadrado Gómez}

Servicio de Medicina Interna. Hospital Universitario Príncipe de Asturias. Departamento de Medicina. Universidad de Alcalá de Henares. Madrid
1. Valero Capilla FA, Masana Marín L Características clínicas y evolutivas de los pacientes asistidos en una consulta especializada de hipertensión arterial. Experiencia de 10 años. An Med Interna (Madrid) 1999; 16: 498-503.

\section{Síndrome de Turner con isocromosoma $\mathrm{X}$ : diagnóstico tardío}

\section{Sr. Director:}

El síndrome de Turner es la alteración del cromosoma X más frecuente en las mujeres afectando aproximadamente a un 3\% de los embriones de sexo femenino aunque su frecuencia entre las recién nacidas se reduce a 1 de cada 1.500/2.500 ya que se calcula que solo un $15 \%$ de los embriones con cariotipo 45, XO llegan a término (1). Como en otras alteraciones genéticas, este síndrome puede presentar cariotipos diversos y por lo tanto una gran variedad de presentaciones fenotípicas. Los estigmas somáticos son generalmente más leves en las pacientes con mosaicismo y en algunas alteraciones estructurales del cromosoma $X$ (2). La falta de "estigmas" característicos puede llevar a un diagnóstico tardío y un consecuente retraso en el tratamiento (3). Se describen a continuación las características clínicas de dos pacientes con síndrome de Turner y cariotipo 46,Xi (Xq) cuyo diagnóstico se realizó tardiamente.

La paciente n. $^{\circ} 1$, una mujer de 47 años, acudió a la consulta por un hipertiroidismo. Entre los antecedentes personales destacaba una amenorrea primaria que no había sido estudiada con anterioridad. No existían antecedentes familiares de talla baja y/o endocrinopatías. En la exploración física la paciente presentaba un aspecto sano con fenotipo externo femenino. Su peso era de $50,7 \mathrm{~kg}$, su estatura de $142,8 \mathrm{~cm}$ y sus cifras de tensión arterial eran normales $(130 / 85 \mathrm{mmHg})$. La paciente no presentaba rasgos dismórficos mayores llamando únicamente la atención una auscultación cardiopulmonar con tonos fuertes y soplo sistólico de intensidad leve. La analítica hormonal confirmó la existencia de un hipertiroidismo autoinmune y de un hipogonadismo hipergonadotropo. El análisis de su cariotipo mostró la presencia de una fórmula cromosómica 46,X iso (Xq) en todas las metafases estudiadas (Fig.1a). La única malformación asociada de la paciente era la presencia de insuficiencia aórtica de grado II, insuficiencia tricuspídea ligera con hipertensión arterial pulmonar moderada, contractilidad cardiaca hiperdinámica e insuficiencia mitral ligera.

La paciente n. ${ }^{\circ}$, de 15 años, acudió a la consulta por talla baja. No existían antecedentes familiares de talla baja y/o endocrinopatías. En la exploración física se observó una paciente de aspecto sano con fenotipo externo femenino, con un peso de 45,2 $\mathrm{kg}$, una estatura $146,2 \mathrm{~cm}$, unas cifras de tensión arterial normales $(110 / 80 \mathrm{mmHg})$, ausencia de caracteres sexuales secundarios, signos de psoriasis en las extremidades y un discreto pterigum colli. La paciente no había tenido la menarquia. El estudio del cariotipo confirmó la existencia de un isocromosoma de brazos largos del cromosoma X [46,Xi (Xq)] (Fig. 1b). En esta paciente el ecocardiograma resultó ser normal y la ecografía abdominal reveló solo un útero atrófico y unos anejos hipoplásicos. La analítica hormonal puso de manifiesto la existencia de un hipotiroidismo subclínico con unos anticuerpos antitiroideos positivos así como un hipogonadismo hipergonadotropo. En esta paciente el diagnóstico se realizó más precozmente por lo que se instauró tratamiento estrogénico. En el momento del diagnóstico la maduración ósea era completa por lo que no fue posible instaurar tratamiento con hormona de crecimiento.

Las manifestaciones clínicas en las pacientes con Síndrome de Turner con isocromosoma X pueden ser muy variables (2). La 


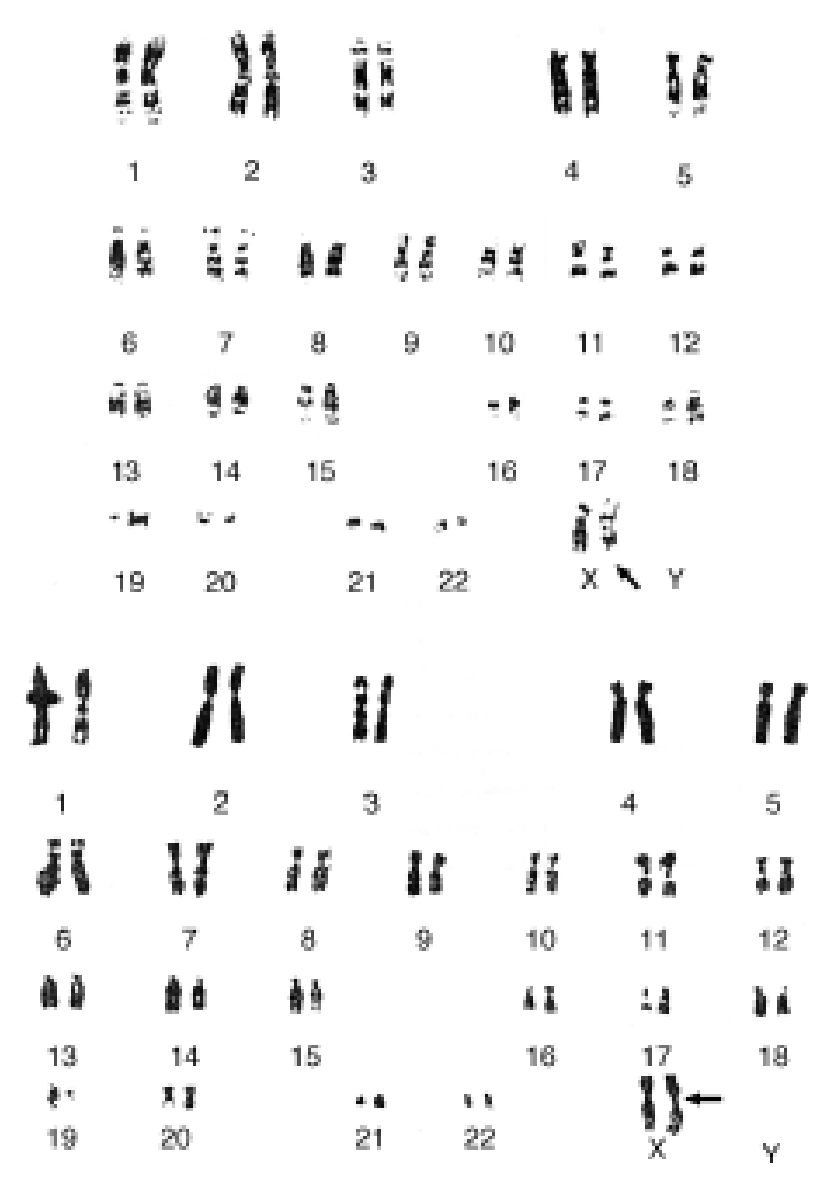

Fig. 1. Cariotipos de la paciente $n .01$ (a) y de la paciente $n .02$ (b) en los que se confirma la existencia de un síndrome de Turner por isocromosoma X. Los cariotipos fueron extraídos tras cultivo durante 72 horas de linfocitos y posterior estimulación con fitohemaglutinina.

falta de "estigmas" característicos puede llevar, como en estos dos casos al diagnóstico tardío. La amenorrea primaria por disgenesia gonadal y el déficit estatural son las características de más frecuente aparición, dándose casi en el $100 \%$ de los casos descritos en la literatura aunque pueden darse también pacientes con ciclos menstruales espontáneos (4). La coartación aórtica y los edemas linfáticos periféricos son infrecuentes en las pacientes 46 , Xi (Xq). Además, en las pacientes con este cariotipo el característico "cuello alado" cuando aparece, suele ser poco marcado como se vió en la paciente $n .^{\circ} 2$. Son frecuentes sin embargo las enfermedades relacionadas con trastornos autoinmunes y especialmente las alteraciones tiroideas (5). Dado que aproximadamente el 17\% de las pacientes con síndrome de Turner tiene un isocromosoma $\mathrm{X}$ y que esta variedad genotípica cursa con rasgos fenotípicos más leves (6), es necesario tener presente esta entidad en aquellas pacientes fenotípicamente normales que presentan retraso estatural y/o del desarrollo. Un diagnóstico más precoz permitirá instaurar a tiempo los tratamientos adecuados.

\section{P. Gil del Álamo, I. Cano Rodríguez}

Servicio de Endocrinología y Nutrición. Hospital de León. León

1. Cockwell A, MacKenzie M, Youings S, Jacobs P. A cytogenetic and molecular study of a series of 45,X fetuses and their parents. J Med Genet 1991; 28: 152-155.

2. Mensah-Ado I, Lauhbouet M D, Lokrou A, Ehouman A, Morlier G.
Syndrome de Turner: Mosaique et isochromosome q chez une jeune africaine. Med Trop 1994; 54: 349-351.

3. Tóth PP, Jogerst GJ. Identification of Turner's Syndrome in an elderly woman. Arch Fam Med 1996; 5: 48-51.

4. Ranke MB. An introduction to Turner's syndrome. Oxford, England: Oxford Clinical Communications, 1989.

5. Saenger MD. Turner's syndrome. N Engl J Med 1996; 335 (23): 17491754 .

6. Saenger $P$. The current status of diagnosis and therapeutic intervention in Turner's syndrome. J Clin Endocrinol Metab 1993; 77: 297-301.

\section{Dolor abdominal agudo en el anciano}

\section{Sr. Director:}

La consulta por dolor abdominal agudo en el anciano supone un reto por su manifestación insidiosa, con escasos síntomas y signos, y los datos poco específicos que se obtienen en las pruebas básicas urgentes (hemograma, bioquímica y radiografías simples).

A propósito de un caso vamos a repasar las características que hacen diferente el dolor abdominal agudo en los ancianos, sobre todo las dificultades que vamos a encontrar para hacer un diagnóstico exacto.

Mujer de 89 años de edad con antecedentes de DMNID, EPOC, Insuficiencia Cardiaca y estreñimiento. Ingresa por un aumento progresivo de la disnea hasta hacerse de reposo, con ortopnea de 3 almohadas y aumento de edemas en miembros inferiores, coincidiendo con un cuadro catarral de vías altas. Al ingreso la enferma se encontraba afebril, taquipnéica, con trabajo respiratorio, cianosis e ingurgitación yugular. En la auscultación cardiaca estaba arrítmica, a $140 \mathrm{Ipm}$ y en la pulmonar se auscultaban crepitantes en 2/3 inferiores de ambos hemitórax. La exploración abdominal era normal, con ruidos hidroaéreos presentes, sin masas ni visceromegalias, ni dolor a la palpación. Presentaba edemas en miembros inferiores con fóvea hasta rodillas. Hemograma: leucocitos 16.000 (Gr 86\%, L 6\%, Mo 2\%), Hb 14,6 g/dl, Hto $42 \%$, VCM 89. Plaquetas 123.000. Bioquímica con glucemia $136 \mathrm{mg} / \mathrm{dl}$, urea $144 \mathrm{mg} / \mathrm{dl}$, creatinina $1.2 \mathrm{mg} / \mathrm{dl}$, siendo los valores de GOT, GPT, GGT, F. alcalina, LDH, Na y K normales. Coagulación con fibrinógeno: 610 g/l, resto normal. ECG: Fibrilación auricular con respuesta ventricular a $140 \mathrm{lpm}$. La Rx de tórax presentaba cardiomegalia con infiltrado intersticial bilateral. Se inicia tratamiento con oxigenoterapia, furosemida, digoxina y tratamiento antibiótico con amoxicilin clavulánico, con mejora progresiva de la enferma, desapareciendo paulatinamente los edemas en miembros inferiores y disminuyendo la sintomatología. A los 7 días del ingreso la enferma refiere dolor en hemiabdomen izquierdo. En la exploración se encuentra afebril, con TA 120/70, bien perfundida e hidratada. El abdomen esta distendido, con escasos ruidos y dolor a la palpación en hipocondrio izquierdo, sin signos de irritación peritoneal. No refiere sintomatología urinaria, siendo la puñopercusión renal negativa. Se realiza un control analítico urgente, con hemograma: leucocitos $9.400(\mathrm{Gr}$ $86 \%$, L 17,7\%, Mo 6\%), Hb 13,1 g/dl, Hto 37\%, VCM 89 fl, Plaquetas 167.000. Bioquímica: glucosa $76 \mathrm{mg} / \mathrm{dl}$, urea $74 \mathrm{mg} / \mathrm{dl}$, creatinina $1,2 \mathrm{mg} / \mathrm{dl}$, amilasa $28 \mathrm{UI} / \mathrm{l}$, Na y K normales. Niveles de digoxina >2. GAB (con $\mathrm{FiO}_{2} 24 \%$ ): $\mathrm{pH} 7,43, \mathrm{pCO}_{2} 64, \mathrm{pO}_{2} 73$, $\mathrm{HCO}_{3}$ 43. Se realiza una Rx de Abdomen (imágenes de litiasis en hipocondrio derecho), y una Ecografía abdominal urgente, donde se aprecia una vesícula biliar con imágenes litiásicas en su interior, sin signos de colecistitis, y riñones de tamaño y ecogenididad normales, siendo el resto de la exploración normal. Se solicita valoración por el Servicio de Cirugía, y ante la sospecha de diverticulitis, se inicia tratamiento con reposo intestinal y tratamiento antibiótico de amplio espectro frente a aerobios y anaero- 
bios. A los dos días la enferma se encuentra afebril, estable hemodinámicamente, con diuresis conservada, pero presenta taquipnea y refiere intenso dolor en hipocondrio izquierdo, presentando abdomen distendido, timpánico, sin ruidos hidroaéreos, palpándose una masa mal delimitada en hiponcondrio izquierdo. En la Rx abdominal urgente no se observan imágenes sugestivas de obstrucción intestinal, y se realiza una Rx de tórax presentando aire libre intraperitoneal. La enferma es sometida a cirugía urgente, presentando diverticulitis con perforación intestinal y peritonitis fecaloidea.

Mientras que en el paciente joven la causa más frecuente de dolor abdominal es el dolor abdominal inespecífico y la apendicitis, en los ancianos, en la mayoría de las series, es la patología biliar y la obstrucción intestinal la responsable de consulta por dolor abdominal, además de otras patologías que son muy infrecuentes en los jóvenes, como la patología tumoral o la vascular (Tabla I) (1-6).

No solamente es diferente la etiología del dolor abdominal en el anciano respecto a los jóvenes, sino que son numerosas las dificultades a la hora de valorar adecuadamente a éstos enfermos $(7,8)$, pudiéndolas resumir en un decálogo:

1. Al contrario que los enfermos jóvenes, que consultan nada más presentar la sintomatología, los ancianos suelen consultar pasadas horas o días del inicio de la clínica.

2. Los ancianos suelen presentar otras enfermedades de base (hasta el 65\% se acompañan de al menos una enfermedad acompañante), que se descompensan y hacen difícil la valoración.

3. Deseo, tanto por parte del enfermo como del médico, de un manejo conservador, evitando tanto estudios como tratamientos innecesarios.

4. A veces es imposible o difícil de obtener los datos de la anamnesis, porque algunos de los enfermos presentan demencia, patología neurológica o alteración del nivel de conciencia.

5. La sintomatología suele ser de presentación subaguda y menos intensa. Los ancianos tienen una menor sensibilidad para el dolor, de forma que no suelen consultar por dolor de inicio agudo e intenso, sino por dolor larvado (4).

6. Escasez de signos físicos en la exploración. Los ancianos no suelen presentar signos de abdomen agudo, siendo infrecuente la presencia de abdomen en tabla. Suelen presentar dolor abdominal difuso, debiendo prestar atención a la defensa involuntaria y al dolor de rebote como signos indirectos de posible peritonitis.

7. Falta de alteraciones en los signos vitales. No suelen presentar fiebre ni taquicardia, siendo más frecuente encontrar hipotermia.

8. Es infrecuente la presencia de leucocitosis en el hemograma. Se suelen encontrar alteraciones hidroelectrolíticos y aumento de la creatinina, lo que puede llevarnos a diagnosticar casos de íleo paralítico secundario a alteraciones hidroelectrolíticas, en vez de pensar que son la consecuencia de la patología abdominal.

9. La Rx de Abdomen es anormal solo en el 10\% de los casos. En los casos de sospecha de obstrucción intestinal, es donde más utilidad encontramos en la Rx de abdomen, aunque en las fases iniciales de la obstrucción la Rx puede ser normal sin observarse niveles hidroaéreos.

10. No solamente debemos pensar en patología abdominal, sino que puede ser dolor abdominal referido, procedente de patología extrabdominal, por lo que se debe realizar una Rx de tórax y un ECG. En los casos de dolor abdominal agudo, la combinación de una placa abdominal en decúbito supino y una placa de tórax frontal es la que más precisión diagnóstica tiene, llegando a un $98 \%$ (9).

Si la causa del dolor abdominal no está aclarada debemos sospechar la posibilidad de patología tumoral o vascular. Aproximadamente el $10 \%$ de los pacientes mayores de 50 años con dolor abdominal no filiado son de causa neopláscia, y el $10 \%$ de las consultas en mayores de 70 años son por patología vascular (1). La patología vascular suele presentarse en paciente con factores de riesgo cardiovascular, con dolor abdominal severo no localizado y con pocos hallazgos físicos. Como screening se ha sugerido la acidosis metabólica y la elevación de la fosfatasa alcalina, LDH y amilasa, siendo la Arteriografía la prueba diagnóstica con mayor sensibilidad y especificidad (10).

En nuestro caso, la enferma no presentó fiebre ni signos de inestabilidad hemodinámica. La ausencia de leucocitosis posiblemente se pueda justificar por el tratamiento antibiótico que estaba recibiendo. En la exploración física no presentaba signos de irritación peritoneal, y solamente al tercer día, coincidiendo con un aumento del dolor abdominal, se palpaba una masa en hipocondrio izquierdo, en relación con un probable plastrón inflamatorio,

\begin{tabular}{|c|c|c|c|c|c|c|}
\hline \multicolumn{7}{|c|}{ TABLA I } \\
\hline$\%$ & $\begin{array}{c}\text { PONKA } \\
(1961-62) \\
\end{array}$ & $\begin{array}{l}\text { FENYO } \\
(1977-78)\end{array}$ & $\begin{array}{c}\text { BENDER } \\
(1980-84) \\
\end{array}$ & $\begin{array}{c}\text { IRVIN } \\
(1984-87) \\
\end{array}$ & $\begin{array}{l}\text { MUIÑO } \\
(1988)\end{array}$ & $\begin{array}{l}\text { DO M BAL } \\
(1982-93) \\
\end{array}$ \\
\hline Dolor inespecífico & & & & 22,5 & 9,2 & 15,7 \\
\hline Apendicitis & 8 & 3,5 & 4 & 4,2 & 0,7 & 15,2 \\
\hline O bstrucción & 17,5 & 10,7 & 33 & 28 & & 12,3 \\
\hline Urológico & & & & 3,2 & 16,1 & \\
\hline Biliar & 27,5 & 26 & 19 & 8,9 & 15,4 & 20,9 \\
\hline Diverticular & 10 & 7 & & 8,5 & & 5,5 \\
\hline Trauma abdominal & & & & 0,4 & & \\
\hline Cáncer abdominal & & & 2 & 5,5 & & 4,1 \\
\hline Ulcus péptico & 10.5 & 8,4 & 10 & 6,1 & 5,4 & \\
\hline Pancreatitis & 7,5 & 4,1 & & 3,8 & & 7,3 \\
\hline Aneurisma Aorta & & & 1 & 3 & & \\
\hline Ginecológico & & & 1 & 0,2 & & \\
\hline Ell & & & & 1,1 & & \\
\hline Gastroenteritis & & & & 0 & 11,5 & \\
\hline Vascular & & & 6 & 1,5 & & 2,3 \\
\hline Hernia & 5,5 & 4,8 & 18 & & 18,5 & 3,1 \\
\hline M édico & & & & 1,1 & & \\
\hline M isceláneo & 13,5 & 35,5 & & 1,9 & & \\
\hline
\end{tabular}


presentando abdomen distendido y con escasos ruidos hidroaéreos. Durante los tres días de seguimiento del dolor abdominal se hicieron Rx de abdomen seriadas, sin aportar nuevos datos a los ya presentes.

\section{Gómez Antúnez, A. Zaera Olombrada, V. Viña, T. Pas- cual, A. Marco Mur}

Servicio de Medicina Interna. Hospital Virgen de la Torre. Madrid

1. Dombal FT. Acute abdominal pain in the elderly. J Clin Gastroenterol 1994; 19: 331-335.

2. Muiño Miguez A, Rodríguez de Castro E, González Ramallo VJ, Lázaro Bermejo C, Hergueta Martín-Artajo L. Dolor abdominal en el servicio de urgencias. Sequimiento de pacientes con dolor no filiado. An Med Interna (Madrid) 1989; 6: 23-25.

3. Irvin TT. Surgical audit ofthe acute abdomen. Br J Surg 1989; 76: 11211125.

4. Bender JS. Cuadro abdominal agudo. Med Clin North Arner 1989; 6: 1549-1558.

5. Fenyo G. Acute abdominal disease in the elderly. Am J Surg 1982; 143: 751.

6. Ponka JL, Welborn JK, Brush BE. Acute abdominal pain in aged patients: an analysis of 200 cases. J Am Geriatric Soc 1983; 11: 993.

7. Sanson TG, O Keefe KP. Evaluation of abdominal pain in the elderly. Emerg Med Clin North Am 1996; 14: 615-627.

8. Cooper GS, Shales DM, Salata RA. Intraabdominal infection: differences in presentation and outcome between younger patients and the elderly. Clin Infect Dis 1994; 19: 146-148.

9. Brazaitis MP, Dachman AH. Evaluacion radiográfica del dolor abdominal agudo de origen intestinal: criterio clínico. Med Clin North Am 1993; 5: 997-1019.

10. Pearigen PD. Unusual causes of abdominal pain. Emerg Med Clin North Am 1996; 14: 593-613.

\section{Respuesta paradójica sistémica a tratamiento tuberculostático, a propósito de un caso}

\section{Sr. Director:}

La Respuesta Paradójica Sistémica (RPS) al tratamiento (tto.) tuberculostático es un síndrome infrecuente caracterizado por desarrollo de lesiones tuberculosas no existentes antes de la terapia o bien por empeoramiento de las iniciales con una pauta adecuada. Este fenómeno puede estar en relación con una alteración de la reactividad inmunológica local producida por liberación de metabolitos por parte de las bacterias atacadas por fármacos, por una depresión de la inmunidad celular puesta de manifiesto por linfopenia y anergia. Las localizaciones más frecuentes son: ganglionar, meníngea, renal o lesiones pulmonares graves, pero se ha visto que pueden aparecer en cualquier órgano, dando lugar a dificultades diagnósticas, no sólo antes del diagnóstico microbiológico inicial, si no posteriormente, ante la diversidad de lesiones con distinta evolución $(1,2)$. Todo ello nos lleva a presentar este caso: paciente de 35 años con historia iniciada, un año antes, en forma de lesiones pruriginosas en glande, depresión, dolor torácico e hipo-epigástrico, náuseas, ritmo intestinal alternante, síndrome general con pérdida de $15 \mathrm{~kg}$, fiebre y lesiones duras, dolorosas en hipocondrio izquierdo (HI), cresta ilíaca y pierna derecha, motivo por el que fue visto en otro centro, dónde se realizaron estudios, incluyendo Ziehl en esputo, con resultado positivo para Mycobacterium Tuberculosis, instaurándose tto. con rifampicina, isoniazida y pirazinamida (PRZ). Ante la persistencia de síndrome general y dolor tóraco-abdominal después de 1,5 meses de tto. se ingresa. Entre sus antecedentes personales destaca: pediculosis pubis, colecistectomía y ser fumador. A su ingreso, en la exploración: paciente delgado, masa supraclavicular derecha, signos de ascitis y nódulos con pérdida de sustancia superficial en HI, espina ilíaca izquierda y extremidad inferior derecha. En analítica destaca: Leucocitos $=6,10^{3} / \mathrm{mm}^{3}$ (1.434 linfocitos $\mathrm{CD}_{4}=876 / \mathrm{mm}^{3}$ ). Plaquetas $\left.=827,10^{3}\right) / \mathrm{mm}^{3} . \quad$ Hemoglobina $=10,5$ $\mathrm{g} / \mathrm{dl} . \mathrm{VSG}=64 /$. Hierro $=35 \mathrm{mg} / \mathrm{dl}$. Ferritina $=356 \mathrm{mg} / \mathrm{dL}$. Ácido úrico=11,5 mg/dl, GGT=62 Ul/L. Albúmina=3,1 g/l ECA=100. CA $15,3=66,2$, con resto de marcadores tumorales normales; serología hepatitis, lúes y VIH negativas. Sedimento urinario: 1-3 hematíes/campo. Cultivos y baciloscopias en sangre, orina, heces y lesiones cutáneas negativos. Multi-test negativo. En estudios de imagen: Rx. Tórax con infiltrados en lóbulo superior derecho y lesiones líticas en $2^{\mathrm{a}}$ y $4^{\mathrm{a}}$ costillas derechas $-2^{\mathrm{a}}$ y $3^{\mathrm{a}}$ izquierdas; Rx. abdomen y ecografía: esplenomegalia y ascitis moderada. Ecografía escrotal normal; ecografía cervical: masa paratiroidea izquierda; TAC tóraco-abdominal: masa cervical que desciende por mediastino posterior alto paratraqueal izquierdo, con infiltrados en ambos lóbulos superiores, lisis costales (Fig. 1) y en vertebras cervicales bajas, adenopatías y lesión abscesificada paraespinal izqda. Se procede a la punción de las masas costal y supraclavicular izqda.: líquido amarillento, negativo para células malignas, cultivos de bacterias, hongos y tinción de Ziehl/Lowestein; lo mismo ocurre con la biopsia de la lesión cutánea (dermatitis aguda abscesificada). Se realizó escaner óseo: acúmulos puntiformes en costilla izqda. Los resultados de colonoscopia, gastroscopia y consulta a Otorrinolaringología fueron normales. Con todo esto se siguió tto. tuberculostático, mejorando clínicamente y radiológicamente, aunque sólo parcialmente. A los nueve meses de tto. presenta, de nuevo, síndrome general con fiebre de tres semanas de evolución, destacando en analítica: $\mathrm{VSG}=23 / 45$. Hierro=28 microg/dl. GOT=60 UI/I. GPT=76 Ul/1. GGT $=418 \mathrm{UI} / \mathrm{L}$ fosfatasa alcalina $=285 \mathrm{Ul} / \mathrm{L}$. Sedimento urinario: 3-7 hematíes/campo. Hemocultivos negativos. En Rx tórax: disminución de infiltrado de lóbulo superior derecho; TAC torácico: ausencia de lesiones líticas y patrón alveolo - nodular en lóbulo superior e inferior izdo., sin otras modificaciones; TAC abdominal: hepatomegalia con adenopatías interaortocava y disminución de la lesión abscesificada paraespinal izqda. Se punciona, otra vez, esta zona: líquido similar al inicial, negativo para células malignas, tuberculosis, bongos y otros gérmenes pero con PCR positiva para $M$. Tuberculosis. Se solicita biopsia hepática: hepatitis granulomatosa con granulomas que presentan células multinucleadas tipo Langerhans. Con todo ello se añade al tto. previo esteroides, a dosis bajas, observándose una mejoría y, tras catorce meses de terapia, presenta una analítica normal, salvo

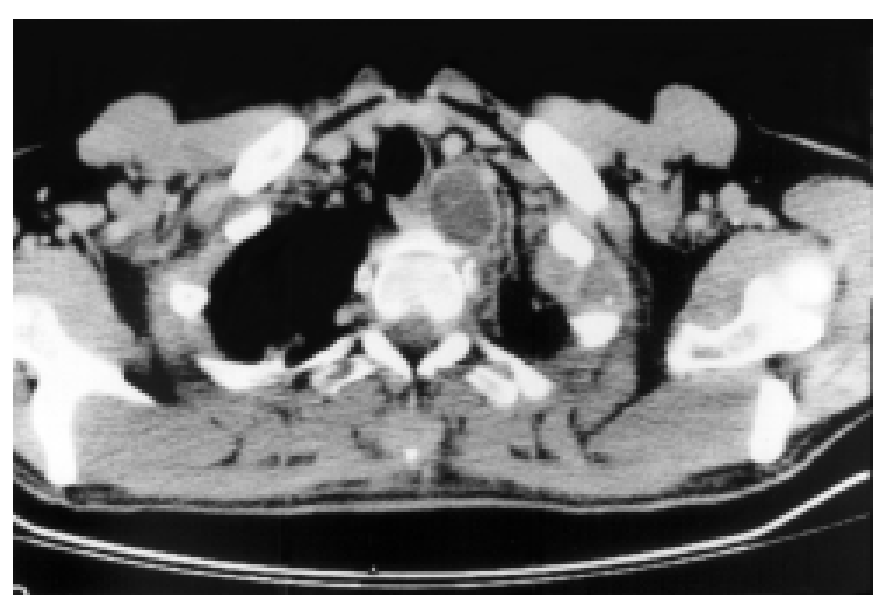

Fig. 1. Masa paratraqueal izqda. necrosada centralmente y lesión lítica costal con masa de partes blandas. 
GGT=129 Ul/1, y TAC tóraco-abdominal con, sólo, fibrosis en lóbulo superior derecho. En nuestro paciente, dada la extensa afectación orgánica (pulmón, hueso, piel, peritoneo y ganglio) y la evolución tórpida, con aparentes recaídas, durante el tratamiento, se plantearon varios aspectos: a) la existencia de una inmunodeficiencia basal, ya congénita, ya adquirida, en forma de infección por el virus de la inmunodeficiencia humana o de neoplasia oculta, descartado convenientemente, como se ha descrito; b) mal cumplimiento del tto. o resistencia al mismo, datos en los que, como describieron J. Rodríguez Baños y cols. y Hilles Smith, debe pensarse siempre, así como, en malabsorción o reacción a drogas, antes de realizar el diagnóstico de RPS $(1,2)$. Nosotros comprobamos el cumplimiento del tto. mediante el seguimiento de las cifras de ácido úrico, mientras estuvo recibiendo PR y después al administrar la medicación en el Hospital, durante dos ingresos. Se realizaron sensibilidades a fármacos, no apareciendo resistencias. Se llevaron a cabo punciones en distintas localizaciones, durante el tto. tuberculostático, siendo los resultados microbiológicos negativos, algo ya descrito en la literatura, donde se dice que aunque existan bacilos éstos no crecen tras un tiempo de terapia (2). A favor de la base inmunológica del proceso iría, tanto la desaparición de lesiones óseas, con disminución de pulmonares y aparición de afectación hepática posterior (2), como la respuesta al tto. esteroideo, lo que se achaca a que los esteroides producen una inhibición de la actividad de las células T Helper I y del factor de necrosis tumoral alfa (TNF); todo ello parece estar de acuerdo con lo apuntado por J. Rodríguez Baño y cols. (1).

C. Gutiérrez del Río, Y. García Alonso*, J. Nuño Mateo, T. Pascual Pascual**, M. L. Ga ${ }^{a}$-Alcalde Fernández, J. Morís de la Tassa

Servicio de Medicina Interna. *Servicio de Radiología. **Neumología. Hospital de Cabueñes. Gijón. Asturias

1. Mendelson J, Mark M. Systemic Paradoxical Response to Antituberculous Drugs: Resolution with Corticosteroid Therapy. CID 1997; 24: 517 519.

2. Smith H. Paradoxical responses during the chemotherapy of tuberculosis J Infect 1987; 15: 1-3.

3. Grange JM, Stanford JL, Rook GAW. Tuberculosis and cancer: parallels in host responses and therapeutic approaches. Lancet 1995; 345: 13501352.

\section{Inhibidores de la HMG-CoA reductasa y disfunción sexual}

\section{Sr. Director:}

Los medicamentos hipolipemiantes pueden ocasionar disfunción sexual (1), habiéndose descritos con más frecuencia en relación con fibratos (2-7) Sin embargo, la asociación con fármacos del grupo de los inhibidores de la enzima 3-hidroxi-3-metilglutaril CoA reductasa (HMG-CoA reductasa) es infrecuente (7).
Creemos de interés comunicar un caso de impotencia asociada al tratamiento con lovastatina.

Varón de 48 años de edad remitido a la consulta para estudio de dislipemia. Tenia antecedentes de HTA controlada con dieta y no existían antecedentes familiares de dislipemia ni de enfermedad cardiovascular precoz. Se diagnosticó de hipercolesterolemia poligénica $y$, al persistir con cifras de colesterol LDL por encima de $180 \mathrm{mg} / \mathrm{dl}$ después de 6 meses de dieta, se inició tratamiento farmacológico con lovastatina a dosis de $20 \mathrm{mg} /$ día presentando, desde entonces, disminución de la libido e imposibilidad para la erección. Se determinaron los niveles de testosterona que estaban discretamente disminuidos y se procedió a la retirada del fármaco con mejoría progresiva de la función sexual y vuelta a la normalidad de los valores hormonales. Posteriormente, se reinstauró tratamiento hipolipemiante con pravastatina, sin aparición de efectos secundarios.

La lovastatina es un fármaco hipolipemiante del grupo de los inhibidores de la HMG-CoA reductasa ampliamente utilizado, que tiene en general buena tolerancia a corto y largo plazo y con escasos efectos secundarios, siendo, los más frecuentes, la elevación leve asintomática de las enzimas musculares y hepáticas sin traducción clínica. La disfunción eréctil ha sido descrita como más frecuente en los pacientes dislipémicos sugiriendo participación en su etiología el uso de fármacos hipolipemiantes, siendo, por otra parte, difícil de distinguir de los efectos de la enfermedad o depresión concomitante (8). En nuestro caso, la mejoría clara de la sintomatología al suspender el fármaco así como, la normalización de los niveles de testosterona y la no reaparición de los síntomas al cambiar de estatina sugiere participación directa del mismo.

\section{G. Pía Iglesias, F.J. Fernández Fernández, E. Ameneiros Lago, P. Sesma Sánchez*}

Servicio de Medicina Interna. Complejo Hospitalario "A. Marcide-Novoa Santos”. *Departamento de Medicina USC. Ferrol. A Coruña

1. Bruckert E, Giral P, Heshmati HM, Turpin G. Men treated with hypolipidaemic drugs complain more frequently of erectile dysfunction. J Clin Pharm Ther 1996; 21: 89-94.

2. Blane GF. Comparative toxicity and safety profile of fenofibrate and other fibric acid derivatives. Am J Med 1987; 83: 26-36.

3. Bain SC, Lemon M, Jones AF. Gemfibrozil-induced impotence Lancet 1990; 336 (8727): 1389

4. Bharani A. Sexual dysfunction after gemfibrozil. BMJ 1992; 305 (6855): 693

5. Figueras A, Castel JM, LaPorte JR, Capella D. Gemfibrozil-induced impotence Ann Pharmacother 1993; 27: 982

6. Alcalá Pedrajas JN, Prada Pardal JL. Impotencia por gemfibrozil. An Med Interna (Madrid) 1998; 15: 175-6

7. Halkin A, Lossos IS, Mevorach D. HMG-CoA reductase inhibitor-induced impotence. Ann Pharmacother 1996; 30: 192.

8. Buajordet I, Madsen S, Olsen H. Statins, the pattern of adverse effects with empahsis on mental reactions. Data from a national and an international database Tidsskr Nor Laegeforen 1997; 117: 3210-3. 